\title{
Correction to: Moon phases and Moon signs do not influence morbidity, mortality and long-term survival, after living donor kidney transplantation
}

A. Kleespies ${ }^{*}$, M. Mikhailov ${ }^{\dagger}$, P. N. Khalil, S. Pratschke, A. Khandoga, M. Stangl, W. D. Illner, M. K. Angele,

K. W. Jauch, M. Guba, J. Werner and M. Rentsch

\section{Erratum}

The authors of this article [1] have stated that the image in Fig. 1 in the main article is incorrect and would like readers to refer to the image in this correction instead.

Received: 19 September 2017 Accepted: 20 September 2017

Published online: 04 October 2017

\section{Reference}

1. Kleespies, et al. Moon phases and moon signs do not influence morbidity,

mortality and long-term survival, after living donor kidney transplantation. BMC Complement Altern Med. 2017;17:440. doi: 10.1186/s12906-017-1944-4.

\footnotetext{
* Correspondence: axel.kleespies@med.uni-muenchen.de

${ }^{\dagger}$ Equal contributors

Department of General-, Visceral-, Vascular- and Transplant Surgery,

University of Munich, Marchioninistrasse 15, 81377 Munich, Germany
} 


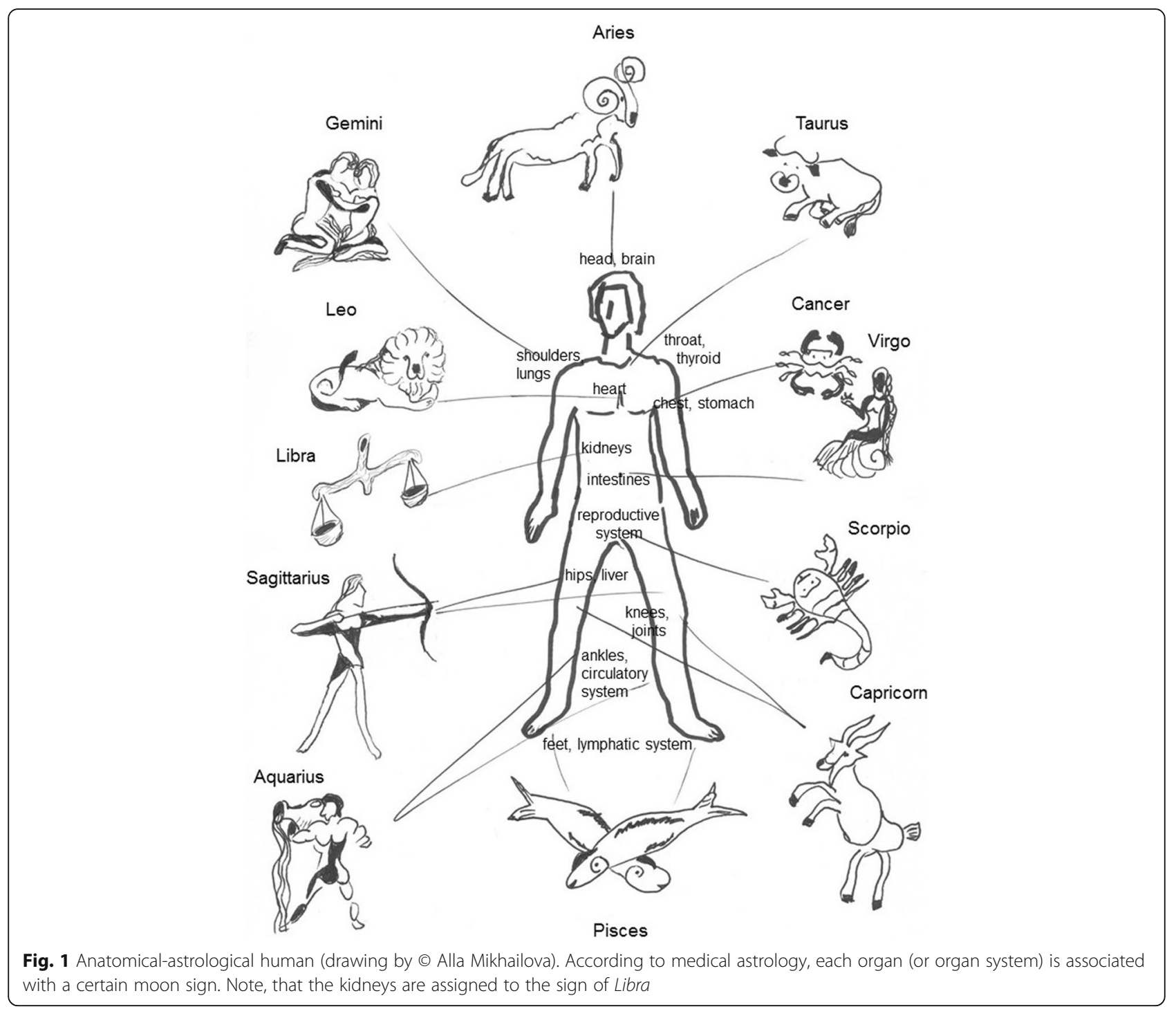

